\title{
CURTINDO E COMPARTILHANDO NO FACEBOOK: UMA ANÁLISE DO DISCLOSURE AMBIENTAL DE EMPRESAS BRASILEIRAS DE CAPITAL ABERTO
}

\author{
Robson Benedito Farias \\ Mestre em Contabilidade \\ Universidade Federal de Santa Catarina - UFSC \\ Florianópolis - Santa Catarina - Brasil \\ farias.robson@gmail.com \\ Gabriela Borges Silveira \\ Mestre em Contabilidade \\ Universidade Federal de Santa Catarina - UFSC \\ Florianópolis - Santa Catarina - Brasil \\ gabi_confiante@yahoo.com.br \\ Cristiane Mallmann Huppes \\ Mestre em Contabilidade \\ Universidade Federal da Grande Dourados - UFGD \\ Dourados - Mato Grosso do Sul - Brasil \\ cristianehuppes@ufgd.edu.br \\ Hans Michael Van Bellen \\ Doutor em Engenharia de Produção \\ Universidade Federal de Santa Catarina - UFSC \\ Florianópolis - Santa Catarina - Brasil \\ hans.michael@ufsc.br
}

\section{RESUMO}

Com o objetivo de verificar a evidenciação de informações ambientais de uma amostra composta por 78 empresas, listadas no Brasil, Bolsa e Balcão (B3), pertencentes ao índice IBrX-100, investigou-se o Índice de Evidenciação Ambiental (IEA), por meio de um instrumento proposto por Bachmann, Carneiro e Espejo (2013), nas páginas oficiais do Facebook no ano de 2016. Em análise complementar, apurou-se a associação entre o IEA e as variáveis: número de seguidores e curtidas; nível de governança; setor; e, sustentabilidade, por meio da técnica de Análise de Correspondência (Anacor). Os resultados demonstraram que 50\% das empresas divulgam informações de caráter ambiental, porém, a média do IEA ficou em $20 \%$. Com relação ao IEA, os itens mais evidenciados foram: programa de gestão ambiental; informação sobre resíduos e desperdícios; declaração das políticas empresariais ambientais; e, impactos ambientais dos produtos e processos, poluição atmosférica, das águas, sonora, visual. Para a relação do IEA e as variáveis selecionadas neste estudo, o número de seguidores e curtidas, setor e sustentabilidade, apresentaram associações significativas. Os principais resultados desta pesquisa sugerem que as empresas atuantes em setores ambientalmente sensíveis; que possuam um número médio de seguidores e que aparentam ser mais comprometidas com a sustentabilidade, praticam um maior IEA. Sob a ótica da Teoria da Legitimidade, é possível perceber que a divulgação de informações ambientais no Facebook ocorra como modo de buscar a legitimidade das ações das empresas, pois essa mídia social, ao englobar diversos stakeholders, tem se tornado uma importante ferramenta na construção da imagem corporativa.

Palavras-chave: Disclosure ambiental. Facebook. Mídias sociais.

\section{LIKING AND SHARING ON FACEBOOK: AN ANALYSIS OF THE ENVIRONMENTAL DISCLOSURE OF BRAZILIAN OPEN CAPITAL COMPANIES}

\begin{abstract}
The objective of this paper is to provide evidence regarding Brazilian companies using Facebook as a communication and engagement channel for environmental disclosure. The data was composed of 78 Brazilian companies listed on the IBrX-100 index by Brazil, Bolsa e Balcão (B3) that has Facebook pages. The Environmental Disclosure Index (EDI) was verified through an instrument proposed by Bachmann, Carneiro and Espejo (2013) in the Facebook pages of companies in 2016. As a complementary analysis, we verified the association between EDI and variables: number of followers and likes, level of governance, sector and sustainability. For this, we used the Anacor test. The main findings indicate that $50 \%$ of the companies disclose environmental information. However the EDI average was $20 \%$. The companies that most disclosed belong to the sectors non-cyclical consumption and basic materials. Regarding EDI and the variables selected in this study, omly the number of followers and likes, sector and sustainability presented significant associations. Our results suggest that companies in the most impacting sectors with an average number of followers and appear to be more committed to sustainability practice a greater EDI through social media Facebook. Based on the Theory of Legitimacy, the environmental disclosure on Facebook involves the search for legitimacy of the actions of companies and social media is an important tool in building corporate reputation.
\end{abstract}

Key words: Environmental disclosure. Facebook. Social media. 


\section{INTRODUÇÃO}

A Securities and Exchange Commission (SEC), que regula o mercado de ações dos Estados Unidos, afirmou que as empresas podem usar as redes sociais para divulgarem informações relevantes aos investidores, desde que estes sejam alertados e que a rede social utilizada seja publicamente acessível e não exclusiva (Zhang, 2015). Ainda, reforça declarações anteriores de encorajamento para utilização das mídias sociais como canais de divulgação de informações aos investidores (SEC, 2013). Essa decisão ocorreu após um episódio que envolveu o CEO do Netflix, Reed Hastings. Ao divulgar em sua página pessoal do Facebook que o Netflix havia passado de 1 bilhão de horas de visualizações pela primeira vez, Hastings contribuiu para que o preço da ação do Netflix subisse de \$ 70,45 dólares para \$ 81,72 dólares (Zhang, 2015; Trinkle, Crossler \& Bélanger, 2015).

É de conhecimento geral que as redes sociais são uma ferramenta com capacidade de grande alcance na divulgação de informações (Kiron, Palmer, Phillips \& Kruschwitz, 2012; Nair, 2011; Eschenbrenner, Nah \& Telaprolu, 2014). Além dos sites institucionais, as redes sociais das companhias contribuem para a redução da assimetria de informação entre a gestão e demais stakeholders (Healy \& Palepu, 2001; Prokofieva, 2015). Dentre o roll de informações divulgadas voluntariamente pelas empresas, as informações de caráter ambiental tiveram demanda significativa devido à pressão feita pela sociedade (Gray \& Bebbington, 2001), e evidenciam-se gradativamente no âmbito corporativo (Hackston \& Milne, 1996; Tinoco \& Kraemer, 2004) desde meados da década de 1970 (Ernst \& Ernst, 1973; Rosa, Ensslin \& Ensslin, 2009; Cho, Freedman \& Patten, 2011).

O disclosure de informações de cunho ambiental constitui-se numa ferramenta de legitimação para as organizações. Na medida em que estas passam a sofrer pressão social, que possa ameçar a legitimidade de suas ações, buscam divulgar um quantitativo maior de informações ambientais, de forma voluntária, como meio de mudar a percepção da sociedade sobre suas atividades (Clarkson, Li, Richardson \& Vasvari, 2008).

A fim de delinear maior disclosure e accountability e, ao mesmo tempo, responder à pressão da sociedade, as empresas divulgam informações sobre sua relação com o meio ambiente em seus websites, por meio de relatórios específicos, tais como o Relatório de Sustentabilidade (RS); e o recente Relato Integrado (RI). Em sua estrutura de relatório, o International Integrated Reporting Council (IIRC), apoia a ideia do uso de tecnologias WEB 2.0 e também de redes sociais, visto que podem, ambas, servir como potenciais ferramentas na divulgação de informações sobre Responsabilidade Social Corporativa (RSC) (IIRC, 2013; Bonsón \& Bednárová, 2015).

Pesquisadores examinaram como as empresas atualmente utilizam as redes sociais para a comunicação com investidores e identificaram que há diferenças entre os canais tradicionais, que são unidirecionais da empresa para o investidor, por meio dos quais a empresa controla a comunicação, em contraste com as redes sociais, que são três vias, ou seja, as empresas divulgam posts ou tweets e os investidores comunicam sua opinião e estas a outros investidores (Blankespoor et al., 2013; Trinkle et al., 2015). Informações divulgadas em redes sociais - sejam de caráter ambiental, social, financeiro ou somente propagandas - passam a sofrer maior monitoramento por parte dos investidores e de outros stakeholders.

Além de ser uma forma alternativa, o uso das redes sociais na prática de disclosure voluntário ambiental, considera o fator custo, já que essa prática pode tornar-se mais econômica do que a divulgação de informações na forma tradiconal (Blankespoor, Miller \& White, 2013).

Dentre essas redes sociais, destaca-se que a mídia Facebook é, atualmente, considerada pelo livro The Facebook Effect, escrito pelo jornalista David Kirkpatrick, a rede social mais bemsucedida, e seu impacto social é maior que redes sociais que a antecedem. De acordo com um levantamento do Pew Research Center (2016), aproximadamente 44\% dos norte-americanos acompanham notícias no Facebook. Em contexto brasileiro, a Quartz - instituição norte-americana que divulga pesquisas relacionadas à nova economia global - divulgou que o Brasil ocupa o

Revista de Gestão Social e Ambiental - RGSA, São Paulo, v. 12, n. 3, p. 21-38, set./dez. 2018. 
primeiro lugar no ranking mundial dos países que mais adquirem informações por meio do Facebook, com $67 \%$ de sua população buscando informação, e cerca de $80 \%$ na utilização da mídia para fins diversos.

Neste contexto, a pesquisa de Zhou, Lei, Wang, Fan e Wang (2014) evidenciou que a divulgação de informações não financeiras representa a categoria que mais cresce no Facebook. Zhang (2015) constatou que empresas maiores e mais rentáveis são mais propensas a terem um maior público no Facebook e Twitter, ou seja, demonstrando um maior alcance de divulgação de suas informações por meio de redes sociais.

Diante das discussões acerca do disclosure voluntário, do aumento na divulgação de informações de caráter ambiental e do advento das redes sociais como forma alternativa de divulgação de informações empresariais, surge a seguinte questão: qual o nível de evidenciação de caráter ambiental promovido pelas empresas por meio da rede social Facebook? Objetivamente, mediante o Índice de Evidenciação Ambiental (IEA), proposto por Bachmann, Carneiro e Espejo (2013), verificou-se este IEA das empresas listadas no IBrX 100 da Brasil, Bolsa e Balcão (B3) no ano de 2016, na rede social Facebook, seguido de uma análise das características associadas a esta evidenciação, tais como o número de seguidores e as curtidas na página, o nível de governança corporativa, o setor de atuação e o índice de sustentabilidade.

Este estudo se justifica por abordar um tema relevante, pois as informações de caráter ambiental são cada vez mais desejadas pelas partes interessadas das empresas (Cho, Roberts \& Patten 2010, Cormier, Gordon \& Magnan, 2004; Epstein \& Freedman, 1994), mas também pela forma interativa que aborda as redes sociais. Este comportamento corporativo é indicativo de que as empresas procuram corresponder às demandas sociais que preservam a continuidade de suas operações de acordo com as expectativas da comunidade em que se encontram, como explica a teoria da legitimidade (Martínez-Ferrero \& García-Sánchez, 2017). Assim, oportuniza que se discuta acerca dessa nova forma de divulgação de informações ambientais, o que ainda é pouco explorado no Brasil.

Ao considerar que a utilização das mídias sociais pelas organizações potencializa a divulgação das informações de modo interativo entre seus usuários, esta pesquisa contribui para identificar o tipo e conteúdo informacional da evidenciação ambiental disponibilizados, de forma voluntária, pelas maiores empresas brasileiras listadas na B3. Outra contribuição importante desta pesquisa consiste em proporcionar o perfil das empresas que mantém a mídia social Facebook como elo de comunicação com seus stakeholders, ao investigar a associação entre o desempenho da divulgação - por meio do IEA - e as características das organizações relativas ao setor de atividade, práticas de sustentabilidade, alcance de divulgação, governança corporativa e porte empresarial.

Além disso, o tema sustentabilidade tem entrado na agenda da alta liderança das empresas nos últimos anos. Em matéria divulgada no jornal Valor Econômico, há dados de uma pesquisa realizada pela Fundação Dom Cabral que mostrou que, entre 2014 e 2016, o número de empresas cuja agenda "sustentabilidade" é liderada pelo CEO cresceu de 51\% para 78\%. Dessa forma, o tema sustentabilidade nas organizações, além de ser atual, demanda por mais pesquisas.

O restante do trabalho está organizado da seguinte maneira: a segunda seção apresenta referencial teórico sobre Disclosure Ambiental via mídias sociais e alguns trabalhos realizados acerca do tema; a terceira parte refere-se aos procedimentos metodológicos empregados; a quarta, apresenta e discute os resultados encontrados; e a quinta, traz as considerações finais, a qual descreve as principais conclusões da pesquisa.

\section{REFERENCIAL TEÓRICO}

Nesta seção, apresentam-se os conhecimentos teóricos combinados a resultados de estudos anteriores para a fundamentação da pesquisa e evolução do conhecimento sobre o tema, sobretudo em empresas brasileiras, delimitado em Disclosure Ambiental via mídias sociais.

\subsection{Disclosure ambiental via mídias sociais}

Revista de Gestão Social e Ambiental - RGSA, São Paulo, v. 12, n. 3, p. 21-38, set./dez. 2018. 
Em uma perspectiva literal, o disclosure significa divulgação. É o ato de expor, de revelar ou divulgar informação. Para a contabilidade, o disclosure constitui-se como o principal elo de comunicação entre os gestores e os demais stakeholders sobre o desempenho da organização, caracterizado pela divulgação de informações quantitativas e/ou qualitativas em seus canais formais e informacionais (Healy \& Palepu, 2001; Múrcia \& Santos, 2009; Gibbins, Richardson \& Waterhouse, 1990).

Essa divulgação de informações voluntárias está ligada à decisão do administrador em divulgar ou não determinada informação para os stakeholders, visto que ele tem acesso a informações importantes sobre a empresa. Ademais, a divulgação está condicionada a circunstâncias favoráveis para que esta se efetive; afinal, divulgar informações voluntárias envolve critérios de julgamento e de escolha sobre como será feita a divulgação (Fields, Lys \& Vincent, 2001; Fuji \& Slomski, 2003; Aharony \& Dotan, 2004; Martinez \& Faria, 2007).

A divulgação de informações pelas empresas pode ocorrer de duas formas: divulgação obrigatória e a voluntária. Portanto, o full Disclosure ou a divulgação completa de informações financeiras compreende tanto as obrigatórias quanto as voluntárias, que sejam úteis na tomada de decisão pelos stakeholders (Mota \& Pinto, 2017).

A teoria da divulgação busca explicar os motivos que levam as empresas a divulgarem informações para o mercado por diferentes meios e os efeitos da divulgação de informações financeiras nos preços das ações, previsão de lucro por ação, além dos fatores que levam à divulgação de informações voluntárias (Salotti \& Yamamoto, 2005; Kothari, Wysochi \& Shu, 2009; Trinkle, Crossler \& Bélanger, 2015). As pesquisas de Verrechia (1983) e Dye (1985) representam alguns dos principais trabalhos que visaram a verificar a divulgação de informações voluntárias pelas empresas.

Dentre alguns dos benefícios da divulgação de informações voluntárias, destacam-se a redução do custo de capital próprio (Botosan, 1997; Hail, 2002; Botosan \& Plumlee, 2005; Gonçalves, Medeiros, Niyama \& Weffortt, 2013) e a redução do custo de capital de terceiros (Healy, Hutton, \& Palepu, 1999; Leuz \& Verrecchia, 2000).

Para Verrechia (2001), a divulgação de informações voluntárias pelas empresas pode ser categorizada em três tipos: a) Divulgação baseada em Associação (Association-based disclosure); b) Divulgação associada a Julgamento (Discretionary-based disclosure); e Divulgação baseada em Eficiência (Efficiency-based disclosure).

A primeira categoria, definida por Verrechia (2001), engloba pesquisas que buscam investigar a relação entre a divulgação de informações e o comportamento de investidores. A segunda analisa os motivos da divulgação, ou seja, busca investigar os fatores e os incentivos que levam os gestores e as empresas a revelarem tais informações ao mercado. A terceira categoria analisa a existência de que alguma forma de evidenciação/divulgação é preferida diante do não conhecimento passado sobre a informação.

Em relação à divulgação voluntária, destaca-se a evidenciação de informações de natureza ambiental. Este tipo de divulgação compreende informações sobre as atividades da empresa que impactam o meio ambiente e como os efeitos dessas transações podem afetar a posição econômica e financeira dos negócios da organização (Bergamini Junior, 2000). Berthelot, Cormier e Magnan (2003) explicam que disclosure ambiental relata passado, presente e futuro do desempenho e da gestão ambiental da organização, tal como as implicações financeiras das ações e das decisões ambientais. Conforme Gray e Bebbington (2001), a divulgação de informação ambiental tornou-se relevante ao longo da década de 1990, permitindo maiores manifestações da interação das empresas com o meio ambiente, visto que permaneceu, em geral, como uma atividade voluntária.

No Brasil, apesar de a publicação de informações ambientais não ser obrigatória, existem recomendações para a divulgação ambiental, tal como o Parecer de Orientação $n^{\circ} 15 / 87$ da Comissão de Valores Mobiliários, Resolução no 1.003/2004 do Conselho Federal de Contabilidade que aprovou a Norma Brasileira de Contabilidade Técnica no 15 (Nbct 15), Despacho n 3034/2006 
da Agência Nacional de Energia Elétrica (Aneel) e Comunicado Externo 017/2011-DP da BM\&FBovespa; atual Brasil, Balcão e Bolsa (B3).

Conforme a NBCT 15, o conteúdo da divulgação ambiental deve abranger itens relacionados aos investimentos e gastos com manutenção nos processos operacionais para melhoria do meio ambiente; os investimentos e gastos com preservação e/ou recuperação de áreas degradadas; os investimentos em educação ambiental; os projetos ambientais; a quantidade de processos ambientais administrativos e judiciais movidos contra a entidade; o valor das multas e das indenizações relativas à matéria ambiental; e os passivos e as contingências ambientais.

Assim, fatores relacionados à notória mobilização sobre a preservação ambiental, pressão governamental e a crescente demanda informacional dos demais stakeholders levaram as empresas a aumentarem suas práticas de responsabilidade corporativa, dentre elas a divulgação de informações ambientais e sociais (Lenzen, Dey \& Murray, 2004). Gray e Bebbington (2001) destacam alguns fatores que podem levar as empresas a divulgarem informações de caráter ambiental de forma voluntária (Figura 1).

\begin{tabular}{|l|l|}
\hline \multicolumn{1}{|c|}{ Razões para evidenciar } & \multicolumn{1}{|c|}{ Razões para não evidenciar } \\
\hline Caso não o faça, a divulgação tornar-se-á obrigatória. & Falta de incentivos. \\
Legitimar suas atividades. & Custo de levantamento e divulgação. \\
Distrair a atenção de outras áreas. & Indisponibilidade de dados. \\
Desenvolver a imagem corporativa. & Evitar divulgar informações confidenciais à concorrência. \\
Antecipar-se a ações regulatórias. & Falta de demanda para a informação. \\
Impacto positivo no preço das ações. & Ausência de requerimentos legais. \\
Benefícios políticos. & Outras prioridades na divulgação de informações. \\
Vantagens competitivas. & \\
Direito dos acionistas e stakeholders à informação. & \\
\hline
\end{tabular}

Figura 1 - Divulgação de informações voluntárias ambientais

Fonte: Adaptado de Gray e Bebbington (2001)

Dentre as razões para evidenciar, apontadas na figura 1, cabe destacar: legitimar suas atividades e desenvolver a imagem corporativa. No que se refere a esses aspectos, a Teoria da Legitimidade motiva as organizações em divulgarem informações de natureza voluntária, como aquelas relativas ao desempenho ambiental, uma vez que, demonstrar o relacionamento da empresa com o meio ambiente, pode ser percebida como forma de legitimar as atividades operacionais perante aos stakeholders; além de preservar a continuidade da organização (Eugénio, 2010).

Nesse sentido, Meyer e Rowan (1977) explicam que as empresas podem adotar diferentes práticas voluntárias em busca da legitimidade organizacional a fim de atingir seus objetivos de continuidade no mercado. Corrobora Islam e Deegan (2008) ao afirmarem que as empresas esforçam-se em certificar que suas ações sejam percebidas por seus stakeholders como legítimas.

Em razão dessas motivações, Gomes, Oliveira, Cruz e Oliveira (2016) consideram que os canais de comunicação podem ser vistos com uma das estratégias da organização, uma vez que a comunicação se configura no diálogo entre todas as partes interessadas e a própria sociedade. Dessa forma, a comunicação, com ênfase na gestão de relacionamento das partes interessadas, constitui-se em uma importante ferramenta na manutenção da gestão da legitimidade organizacional (Suchman, 1995).

Quanto a desenvolver a imagem corporativa, a Responsabilidade Social Corporativa (RSC) atua como uma forma de "seguro" da reputação da organização, visto que a RSC compreende questões éticas e morais referentes à tomada de decisões e ao comportamento corporativo que abordam questões complexas como a proteção ambiental; gestão de recursos humanos; saúde e 
segurança do trabalho; e relações com a comunidade, fornecedores e clientes (Castelo \& Lima, 2006). Dessa maneira, a divulgação de informações que tratam das práticas de RSC auxiliam as companhias a construir uma imagem positiva para seus stakeholders (Orlitzky, Schmidt \& Rynes, 2003).

Segundo Arruda et al. (2015), as redes sociais podem ser consideradas instrumentos úteis para as empresas, em razão de sua gratuidade e da possibilidade de criar uma página específica, na qual o usuário interno pode disponibilizar informações de diferentes assuntos relacionados à organização. Além disso, deve-se mencionar que, atualmente, as redes sociais tomam boa parte do tempo e atenção dos internautas; e o principal objetivo destas é a troca de informações pessoais ou profissionais (Dambrós \& Reis, 2008; Arruda et al., 2015).

Devido ao alcance de público e à quantidade de atores que as redes sociais representam, estudos que discutem a utilização destes meios, sobre o modo como são utilizados e qual o impacto dessas divulgações pelas e nas empresas, fazem parte das discussões no que tange ao full Disclosure de informações financeiras e não financeiras das organizações.

Zhou et al., (2014) analisaram o status atual de adoção de duas plataformas de mídia social popular (Facebook e Twitter) e sua aplicação na divulgação corporativa de empresas listadas em diversos setores nos Estados Unidos. Os resultados mostram que 49\% das empresas adotaram uma das plataformas, enquanto 30\% adotaram as duas plataformas. O estudo também mostrou que 7,06 e 3,45\% das mensagens do Facebook e Twitter, respectivamente, estão relacionadas com divulgações corporativas, e que, entre essas divulgações, as não financeiras representam a categoria que mais cresce no Facebook, enquanto as financeiras aumentaram mais rapidamente no Twitter.

Com o objetivo de verificar a utilização das redes sociais denominadas Wikipédia, Youtube e Facebook e se estas reduzem a assimetria informacional existente entre as empresas e investidores, em seu estudo, Arruda et al. (2015) verificaram as divulgações de 126 empresas de capital aberto listadas na B3; no período de 2006 a 2011, na base de dados da Economatica ${ }^{\circledR}$, da Thomson ONE Analytics ${ }^{\circledR}$ e nas redes sociais citadas. Os resultados mostraram que as redes sociais não têm forte influência nos erros de previsão dos analistas, sugerindo que as companhias brasileiras estão deixando de utilizar as redes sociais como plataforma de divulgação de suas informações financeiras, fato que poderia corroborar enquanto ferramenta para a redução da assimetria informacional.

Zhang (2015) investigou a adoção de novos meios de comunicação (mídias sociais, aplicativos móveis, alertas de e-mail etc.) pelas empresas para divulgar informações corporativas aos consumidores e investidores. Por meio da análise de cluster, as empresas foram diferenciadas entre alta e baixa adoção de novos meios de comunicação, com base no uso de novas mídias. Os resultados mostraram que a divulgação de informações voluntárias da empresa na mídia social está relacionada positivamente ao seu nível de adoção das novas mídias, o que sugere que o engajamento da divulgação de informações com as novas mídias aumenta a influência e o alcance da empresa. Assim, empresas com maiores níveis de disclosure em novas mídias atingem um maior público e o nível de adoção de uma empresa afeta sua intensidade de divulgação de informações sobre mídia social.

As evidências encontradas no referido estudo de Zhang (2015) apontam também que, dentre as novas mídias, o YouTube difere do Twitter e do Facebook. No Twitter e no Facebook, o número de seguidores ou likes podem ser determinados por fatores, tais como tamanho da empresa, rentabilidade, ativo intangível e endividamento. Desse modo, as pessoas são mais propensas a seguirem uma empresa no Twitter ou no Facebook se esta empresa for rentável ou considerada grande. O número de assinantes do YouTube é, principalmente, dependente do número de vídeos enviados para o site, ou seja, quanto mais vídeos forem postados no YouTube, mais views e assinantes uma empresa obterá.

Trinkle, Crossler e Bélanger (2015) examinaram a influência das divulgações e dos comentários por meio das redes sociais sobre as percepções dos investidores não profissionais, com relação às questões de julgamentos de avaliação e credibilidade da administração. Com base na 
teoria de finanças comportamentais, "herd behavior", os autores aplicaram um experimento controlado e concluíram que os comentários em anexo compartilhados nas mídias sociais influenciam as percepções e as reações dos participantes às notícias. Portanto, comentários positivos anexados à boa notícia aumentam a percepção dos investidores a julgamentos de valorização e, comentários negativos ligados às boas notícias podem moderar o efeito da boa notícia. Da mesma forma, comentários negativos ligados à má notícia podem diminuir ainda mais as percepções dos investidores da notícia e seus julgamentos de valorização ou, ainda, os comentários positivos anexados a más notícias podem moderar o efeito das más notícias.

Prokofieva (2015) investigou o efeito da difusão da divulgação corporativa por meio do Twitter. O estudo analisou as empresas de capital aberto da Austrália que utilizaram o Twitter como canal de divulgação corporativa nos anos de 2008-2013. A análise do autor consistiu em avaliar o efeito do uso do Twitter sobre a assimetria da informação, considerando que os investidores encontram como limites tempo e recursos; portanto, não estão cientes de todos os títulos e da divulgação disponível no mercado. Os resultados subsidiaram a conclusão de que divulgar anúncios corporativos por meio do Twitter permite que as empresas atraiam a atenção dos investidores e diminuam esta assimetria.

Bonsón e Bednárova (2015) investigaram o uso do YouTube como um canal de comunicação e engajamento para questões de sustentabilidade (relatórios de sustentabilidade corporativa - RSC) por empresas da zona do euro listadas no índice Stoxx Euro 600, com base na teoria da legitimidade e na teoria dos stakeholders. As principais conclusões indicam que, apesar de seu potencial, o RSC, usando o YouTube, ainda está em estágio inicial, visto que as variáveis independentes utilizadas (relatório GRI, setores ambientalmente sensíveis, índice de sustentabilidade DJSI e a proporção de conselheiros independentes no Conselho da Administração) no referido estudo influenciam apenas a extensão ambiental e não afetam as outras divulgações de sustentabilidade (econômica e social). Ainda, a pesquisa apontou o setor em que a empresa atua, a proporção de conselheiros independentes no Conselho da Administração e o tamanho da empresa como fatores que influenciam a divulgação ambiental via YouTube.

Gomes et al., (2016), embasados em informações divulgadas pela Junta Comercial e Federação da Indústria das empresas baianas, analisaram 256 empresas que implantaram práticas de sustentabilidade nas redes sociais, Facebook, Orkut e Twitter no ano de 2012. Por meio de análise de conteúdo e considerando como teoria norteadora a legitimidade, para garantir e continuar a desenvolver suas operações, as empresas se preocupam em divulgar informações de sua responsabilidade social corporativa, o setor de empresas que lidera o ranking de informações socioambientais na web 2.0 é o industrial. A categoria destas informações são as de Atuação Socioambiental: 3\% das postagens encontravam-se na rede social Facebook e 2\% nos tweets da rede social Twitter.

Mota e Pinto (2017) analisaram o nível de disclosure voluntário das companhias brasileiras de capital aberto, por meio da rede social Twitter, considerando as empresas aderentes em níveis diferenciados de Governança Corporativa da B3, pressupondo que estas possuem maior preocupação com a transparência das informações disponibilizadas aos agentes interessados. Os resultados demostraram a falta de significância estatística para a relação entre o disclosure voluntário no Twitter e a governança corporativa. Logo, é possível concluir que a governança corporativa não influencia a divulgação voluntária. Ressalta-se que, dentre as variáveis de controle (tamanho da empresa, grau de alavancagem e regulação), somente a variável "tamanho" se comportou estatisticamente significante, ou seja, os autores notaram que as empresas maiores têm mais probabilidade de divulgarem informações voluntárias, comparativamente com empresas menores.

Dessa forma, verifica-se que são recentes os estudos que tratam especificamente do disclosure ambiental via Facebook no mercado de capitais brasileiro, e de igual modo percebe-se que as mídias sociais é uma forma contemporânea de divulgação corporativa utilizada pelas empresas.

Revista de Gestão Social e Ambiental - RGSA, São Paulo, v. 12, n. 3, p. 21-38, set./dez. 2018. 


\section{PROCEDIMENTOS METODOLÓGICOS}

O procedimento utilizado para atender ao objetivo proposto foi o de pesquisa descritiva, com abordagem quantitativa. Primeiramente, na coleta dos dados, fez-se o levantamento das publicações postadas no Facebook para compor o IEA; posteriormente, técnicas estatísticas de interdependência para verificar associações entre as variáveis qualitativas. A composição da amostra é apresentada na Tabela 1 e refere-se às empresas listadas no IBrX 100 da B3 no ano de 2016, observadas no período de 1 de janeiro de 2016 a 31 de dezembro de 2016. A escolha da rede social Facebook deve-se à sua evidenciação no resultado de pesquisas, que demonstram que $79 \%$ das 100 maiores empresas da Fortune Global 500 usam pelo menos umas das plataformas de redes sociais mais populares, dentre elas o Facebook (Burson-Marsteller 2010; Du \& Jiang, 2015).

Tabela 1

\begin{tabular}{l|r} 
Composição da amostra & Quantidade \\
\hline Amostra & 100 \\
\hline Total de empresas listadas no IBrX & $(5)$ \\
Exclusão de empresas com ações duplicadas & $(17)$ \\
Exclusão de empresas sem Facebook & 78 \\
Total da amostra &
\end{tabular}

Fonte: Dados da pesquisa (2017)

Na Figura 2, estão relacionadas as 78 empresas que possuem perfis oficiais no Facebook que compõem a amostra.

\begin{tabular}{|c|c|c|c|c|c|c|c|c|c|}
\hline 1 & Ambev & 17 & Copel & 33 & Fleury & 49 & Minerva & 65 & Sabesp \\
\hline 2 & Aliansce & 18 & Cosan & 34 & Gafisa & 50 & MRV & 66 & Ser Educação \\
\hline 3 & Alupar & 19 & Copasa & 35 & Gerdau & 51 & Multiplan & 67 & Smiles \\
\hline 4 & Bco Brasil & 20 & Cia Sid. Nacional & 36 & Gerdau Met & 52 & Natura & 68 & São Martinho \\
\hline 5 & Bco Bradesco & 21 & CVC Brasil & 37 & Gol & 53 & Odontoprev & 69 & Sul América \\
\hline 6 & BB Seguridade & 22 & Cyrela & 38 & Grendene & 54 & P. Açucar & 70 & Suzano \\
\hline 7 & BRF & 23 & Duratex & 39 & Hering & 55 & Petrobrás & 71 & Aes Tiête \\
\hline 8 & Braskem & 24 & Engie Brasil & 40 & Itaú Unibanco & 56 & Marcopolo & 72 & Telefônica \\
\hline 9 & BR Propert & 25 & Eletrobrás & 41 & JBS & 57 & Porto Seguro & 73 & Tim \\
\hline 10 & Banrisul & 26 & Eletropaulo & 42 & Lojas Americanas & 58 & QGEP PART & 74 & TOTVS \\
\hline 11 & B2W Digital & 27 & Embraer & 43 & Light & 59 & Qualicorp & 75 & Trans. Paulistana \\
\hline 12 & BMFBovespa & 28 & Energias Br & 44 & Lojas Renner & 60 & Rumo & 76 & Usiminas \\
\hline 13 & CCR & 29 & Energisa & 45 & M Dias Branco & 61 & Randon & 77 & Vale \\
\hline 14 & Cielo & 30 & Estácio & 46 & Magazine Luiza & 62 & Localiza & 78 & Valid \\
\hline 15 & Cemig & 31 & Eztec & 47 & Multiplus & 63 & Santander & & \\
\hline 16 & CPFL & 32 & Fibria & 48 & Marfrig & 64 & Sanepar & & \\
\hline
\end{tabular}

Figura 2 : Amostra da pesquisa

Fonte: Dados da pesquisa (2017)

Para a coleta das informações ambientais divulgadas pelas empresas, optou-se por um instrumento de coleta já validado em outras pesquisas, denominado Indicador de Disclosure Ambiental (IDA) e que foi desenvolvido por Bachmann et al. (2013). Neste estudo, a nomenclatura 
a ser utilizada será a de Índice de Evidenciação Ambiental (IEA), cujas observações estão descritas na Tabela 2.

Tabela 2

\begin{tabular}{l|l|l}
\multicolumn{1}{c|}{ Composição IDA } & Sim & Não \\
\hline $\begin{array}{l}\text { Índice de evidenciação ambiental } \\
\text { visual) }\end{array}$ & & \\
\hline 2 - Informações sobre resíduos e desperdícios & & \\
\hline 3 - Estabelecimento de metas e objetivos ambientais & & \\
\hline 4 - Programa de gestão ambiental (longo prazo) & & \\
\hline 5 - Declaração das políticas empresariais ambientais & & \\
\hline 6 - Uso eficiente/Reutilização da água & & \\
\hline 7 - Auditoria ambiental & & \\
\hline 8 - Práticas contábeis de itens ambientais tos produtos e processos (poluiáosérica, das águas, sonora, & & \\
\hline 9 - Reserva para proteção ambiental & & \\
\hline 10 - Custos e/ou despesas ambientais Total & & \\
\hline
\end{tabular}

Fonte: Bachmann et al. (2013)

Para a construção do IEA, junto à página oficial do Facebook de cada uma das empresas, verificaram-se as postagens realizadas durante o ano de 2016, com análise de seu conteúdo de acordo com o instrumento de coleta. Atribui-se score 1 quando a empresa divulgou a informação listada e score 0 quando a informação não foi divulgada. Com base nessas observações, os scores foram somados e atribuídas nota para o IEA de cada empresa.

Como análise complementar, verificou-se a associação do IEA com características das empresas, a saber: o número de seguidores (soma do número de seguidores e curtidas na página oficial do Facebook da empresa no dia da coleta dos dados para compor o IEA); a governança corporativa - se a empresa pertence a algum nível diferenciado de governança corporativa da B3 (Novo Mercado, Nível 1, Nível 2 e Tradicional); o setor de atuação conforme classificação na B3; e a sustentabilidade - se a empresa é listada em um nível de sustentabilidade da B3, como Índice de Sustentabilidade Empresarial (ISE), Índice Carbono Eficiente (ICO2). Esta associação foi operacionalizada por meio da Análise de Correspondência (Anacor).

Segundo Fávero, Belfione, Silva e Chan (2009, p. 271), a Anacor consiste em uma técnica de interdependência que “[...] busca estudar a relação entre variáveis qualitativas, permitindo ao pesquisador a visualização de associações, por meio de mapas perceptuais que oferecem uma noção de proximidade, ou associação de frequência, das categorias das variáveis não métricas".

Como pressuposto da Anacor, realizou-se o teste do Qui-Quadrado ao nível de significância de 5\%. Com base no teste Qui-Quadrado, considera-se que duas variáveis possuem associação quando a sig.X2 $=0,000<0,05$. Para operacionalizar o teste do Qui-Quadrado associado ao Anacor, as variáveis IEA e número de seguidores, que são variáveis quantitativas, foram divididas em quartis, resultando nas seguintes categorias: 3 - Nível Baixo $(\mathrm{X} \leq \mathrm{Q} 1)$; 2 - Nível Médio $(\mathrm{Q} 1<\mathrm{X} \leq$ Q3); e 1 - Nível Alto (X >Q3). Como as variáveis: setor de atuação, governança corporativa e sustentabilidade, são qualitativas, o procedimento descrito anteriormente não foi aplicado. 


\section{APRESENTAÇÃO DOS RESULTADOS}

Ao observar o disclosure voluntário ambiental das 78 empresas que apresentam conta oficial na rede social Facebook (Figura 1), constatou-se que há informações desta natureza, contudo, de acordo com o instrumento de coleta para levantar o IEA (Tabela 2), 50\% delas não divulgaram nenhum tipo de informação.

Tabela 3

IEA. Amostra com dados de jan./2016 a dez./2016

\begin{tabular}{c|c|c|c|c|c}
\hline Categoria & $\mathrm{N}$ & Média & Desvio Padrão & Mínimo & Máximo \\
\hline IEA & 78 & $20 \%$ & 0.24 & 0 & $70 \%$ \\
\hline
\end{tabular}

Fonte: Dados da pesquisa (2017)

Pela estatística descritiva do IEA destacada na Tabela 3 , a média de divulgação de informações ambientais pelas empresas no Facebook ficou em $20 \%$. Este percentual é considerado baixo, uma vez que, dentre os dez itens que fazem parte do instrumento que compõe o IEA, a maioria das empresas divulgou dois itens, o que é apontado pelo baixo desvio- padrão. Os valores mínimo e máximo ficaram em 0 e $70 \%$, pois algumas empresas não divulgaram nenhuma das informações consideradas no instrumento utilizado na coleta.

O percentual atendido pelas empresas observadas neste estudo, em cada um dos itens que compõem o IEA, é apresentado na Tabela 4:

Tabela 4

Itens evidenciados. Amostra com dados de jan./2016 a dez./2016

\begin{tabular}{l|c}
\multicolumn{1}{c|}{ Composição IDA } & $\begin{array}{c}\% \text { Itens } \\
\text { Atendidos }\end{array}$ \\
\hline 1 - Impactos ambientais dos produtos e processos (poluição atmosférica, das águas, sonora, visual) & $24 \%$ \\
\hline 2 - Informações sobre resíduos e desperdícios & $35 \%$ \\
\hline 3 - Estabelecimento de metas e objetivos ambientais & $18 \%$ \\
\hline 4 - Programa de gestão ambiental (longo prazo) & $36 \%$ \\
\hline 5 - Declaração das políticas empresariais ambientais & $27 \%$ \\
\hline 6 - Uso eficiente/Reutilização da água & $18 \%$ \\
\hline 7 - Auditoria ambiental & $3 \%$ \\
\hline 8 - Práticas contábeis de itens ambientais & $4 \%$ \\
\hline 9 - Reserva para proteção ambiental & $21 \%$ \\
\hline 10 - Custos e/ou despesas ambientais & $4 \%$ \\
\hline
\end{tabular}

Fonte: Dados da pesquisa (2017)

Depois de apresentar os aspectos que envolvem a incidência dos itens que compõem o IEA, a próxima análise consistiu em realizar o teste do Qui-quadrado entre as variáveis: Seguidores, Governança Corporativa (GC), Setor e Sustentabilidade. O resultado está contido na Tabela 5. 
Tabela 5

Teste Qui-Quadrado. Amostra com dados de jan./2016 a dez./2016

\begin{tabular}{c|c|c|c|c}
\hline Categorias & Seguidores & GC & Setor & Sustentabilidade \\
\hline IEA & $0.000 *$ & 0.290 & $0.001^{*}$ & $0.015^{*}$ \\
\hline
\end{tabular}

Nível de significância $* 5 \%$.

Fonte: Dados da pesquisa (2017)

A variável Nível de Governança Corporativa não apresentou significância estatística, corroborando o que foi percebido por Mota e Pinto (2017), enquanto as variáveis Seguidores, Setor e Sustentabilidade apresentam significâncias estatísticas ao nível de 5\%. Isso indica que elas estão associadas ao IEA divulgado no Facebook que foi levantado nesta pesquisa. Esta associação é apresentada em mapas perceptuais nas figuras que seguem. Primeiramente, a Figura 3 demonstra a associação das variáveis "Setor" e "Seguidores" com o IEA.
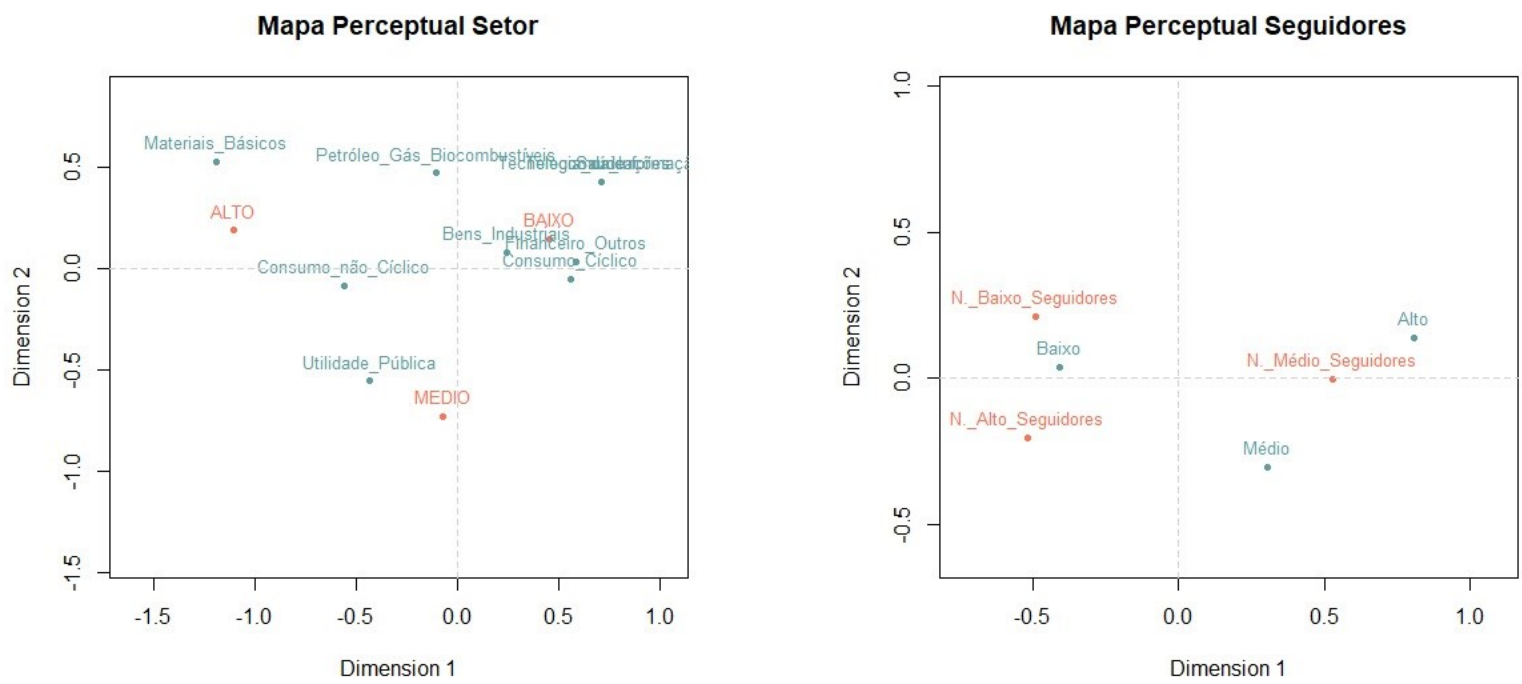

Figura 3 - Mapa perceptual setor e seguidores Fonte: Dados da pesquisa (2017)

Em relação ao número de seguidores, as empresas que apresentaram número médio de seguidores, estão mais associadas ao nível "Alto IEA". Com alto número de seguidores, estão as empresas: Magazine Luiza, Lojas Americanas, Lojas Renner, CVC, Gol, Bradesco e Banco do Brasil, e ficaram associadas ao "Baixo IEA". Destaca-se que estas empresas possuem um grande número de pessoas que acompanham suas páginas no Facebook e usam essa rede social como canal de relacionamento e marketing dos seus produtos e serviços. 


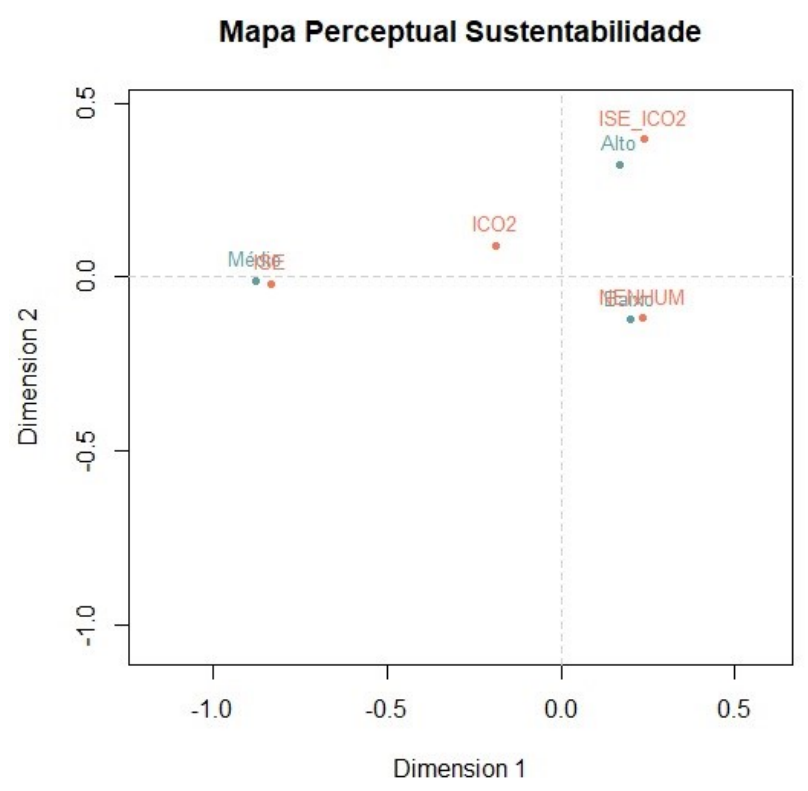

Figura 3 - Mapa perceptual sustentabilidade Fonte: Dados da pesquisa (2017)

A Figura 4 apresenta o mapa perceptual relacionado à sustentabilidade. As empresas, que no ano de 2016 faziam parte do Índice de Sustentabilidade Empresarial (ISE) e do Índice Carbono Eficiente (ICO2) da B3, simultaneamente, apresentaram associação com "Alto IEA". Analisadas somente as empresas listadas no ISE, a associação se classifica como "Médio IEA". Por fim, as empresas que não estavam listadas em nenhum índice de sustentabilidade da B3 apresentaram associação com "Baixo IEA". Estes resultados corroboram com o estudo de Gray e Bebbington (2001), no qual se espera que as empresas mais comprometidas com a sustentabilidade obtenham maior nível de evidenciação como forma de legitimar suas atividades.

\section{DISCUSSÃO DOS RESUTADOS}

$\mathrm{Na}$ análise descritiva, verificou-se que a média do IEA é de $20 \%$, o que sinaliza que as maiores empresas brasileiras pouco têm utilizado a rede Facebook como canal de divulgação das informações de caráter ambiental, o que vai ao encontro do estudo de Arruda et al. (2015), no qual se menciona que as companhias brasileiras estão deixando de utilizar as redes sociais para divulgar informações corporativas.

Todos os 10 itens observados foram evidenciados pelas empresas. Assim, verificou-se que as empresas utilizam a rede social Facebook para dar transparência sobre suas ações como forma de se legitimar (Bonsón \& Bednárova, 2015; Gomes et al., 2016; Mota \& Pinto, 2017). Isto pode estar ligado ao crescimento do uso de redes sociais, da maior abrangência de públicos com diferentes características alcançadas nessa forma de evidenciação, quando comparadas com as formas tradicionais de divulgação.

O item que obteve maior incidência de divulgação foi o " 4 - Programa de gestão ambiental - longo prazo", com 36\% das empresas, que relatam que seguem as normas de certificação ISO 14001. Por exemplo, a empresa Engie descreve: "A Engie possui um Sistema Integrado de Gestão da Qualidade e Meio Ambiente, certificado pelas normas NBR ISO 9001 (norma de qualidade) e NBR ISO 14001 (norma ambiental) para todas as usinas que a Companhia opera".

O segundo item mais relatado foi o "2 - Informação sobre resíduos e desperdícios" com $35 \%$. A divulgação relaciona-se a políticas para tratamento e diminuição de resíduos. Como exemplo, a empresa Braskem divulgou em seu Facebook, a seguinte informação: "Geramos, em 
média, 2,2 vezes menos resíduos do que a indústria química brasileira, que é de 4,8 kg/t. Aproveite e conheça as nossas iniciativas para minimizar e dar a destinação correta aos resíduos em nosso site: www.braskem.com".

Com incidência de $27 \%$ de ocorrência está o item "5 - Declaração das políticas empresariais ambientais", que traz informações sobre o que a empresa faz e/ou irá fazer sobre o meio ambiente.

Relativo ao item "1 - Impactos ambientais dos produtos e processos (poluição atmosférica, das águas, sonora, visual)", com $24 \%$, destaca-se a informação trazida pela empresa Vale, a qual relata que: "Na Malásia, substituímos os veículos comuns por buggies elétricos como meio de transporte interno. A iniciativa faz parte da Meta Carbono, que consiste em reduzirmos em 5\% as emissões diretas de gases do efeito estufa até 2020". Destaca-se a dificuldade de medir impacto ambiental e o custo relacionado a obtenção dessa informação, o que pode contribuir para que poucas empresas tragam essas informações.

Os demais itens tiveram menor evidenciação. Com relação ao item 7, que observa a Auditoria Ambiental, apenas 3\% das empresas divulgaram esse item. A empresa Marfrig trouxe a seguinte informação: “Anualmente a DNV GL, líder mundial em certificação, audita e certifica as unidades da Marfrig nos requisitos mais exigentes de meio ambiente, responsabilidade social e segurança do trabalho. Assim, garantimos a excelência na gestão responsável de nossas operações". Essas auditorias deveriam trazer o enfoque do impacto ambiental das organizações; no entanto, a maioria delas apenas enfoca os sistemas de gerenciamento e não os efeitos ambientais reais.

Sobre o item "10 - Custos e/ou despesas ambientais", destaca-se a publicação da empresa Vale, que divulgou um vídeo sobre o acordo entre a Vale, a Samarco e a BHP com os governos de Minas Gerais (MG) e do Espírito Santo (ES) e a União, firmando o repasse de R\$ 4,4 bilhões de reais para custear projetos socioambientais: "O plano de ações compensatórias terá duração de 15 anos. "Entre 2016 e 2030, o aporte financeiro anual será, no mínimo, de R\$ 240 milhões".

Embora todos os itens que compõem o IEA possuam importância no contexto ambiental, observa-se que o item " 6 - Uso eficiente/Reutilização da água" foi evidenciado por $18 \%$ das empresas. Esse item trata do conceito de ecoeficiência, isto é, quando o uso de recursos é dado de forma mais eficiente a fim de reduzir custos econômicos e impactos ambientais.

As empresas que apresentaram maior IEA, 70\% de divulgação, são: Braskem, CCR Vias, Duratex, Sanepar e Vale. As que apresentaram 60\% dos itens observados são: Ambev, BRF, Cemig, Gerdau e Suzano Papel e Celulose. Cabe a estas empresas a observação de que pertencem a setores considerados mais sensíveis, porque desenvolvem atividades que estão ligadas ao meio ambiente, o que corrobora para a evidenciação de mais informações para sociedade, resultado este já levantado por Lenzen, Dey e Murray (2004), Gomes et al., (2016) e Bonsón e Bednárova (2015).

Constata-se que as empresas que tiveram "Alto IEA", pertencem aos setores de materiais básicos e consumo não-cíclico. No setor de materiais básicos, estão as empresas do segmento de siderurgia, papel e celulose, minério e petroquímicos, a saber: Vale, Braskem, Gerdau, Duratex. Já no setor consumo não-cíclico temos as seguintes empresas: Ambev, BRF, Marfrig, São Martinho. As empresas que apresentam "Médio IEA" pertencem ao setor de utilidade pública, cujas atividades envolvem a energia elétrica e o saneamento. Como "Baixo IEA", a associação ocorre para as empresas dos setores: financeiros e outros, consumo cíclico, telecomunicações e bens industriais. Como se observa, o setor influencia na divulgação de caráter ambiental pelas empresas via rede social. Esse resultado corrobora com os estudos de Bonsón e Bednárova (2015), Zhang (2015) e Gomes et al. (2016).

Como foi possível verificar, as empresas buscam novas alternativas para legitimar suas ações, pois, mesmo que a informação divulgada no Facebook não seja tão completa quando divulgadas por meio de relatórios, as empresas se esforçam no sentido de certificar que suas ações sejam percebidas por seus stakeholders como legítimas (Islam \& Deegan, 2008).

Nesse sentido, Meyer e Rowan (1977) explicam que as empresas podem adotar diferentes práticas voluntárias em busca da legitimidade organizacional a fim de atingir seus objetivos de continuidade no mercado. 


\section{CONSIDERAÇÕES FINAIS}

Este estudo investigou a divulgação de informações ambientais realizadas pelas empresas brasileiras de capital aberto por meio da rede social Facebook e a sua associação com algumas características das empresas.

Para capturar as informações ambientais divulgadas pelas empresas no Facebook, utilizou um instrumento com 10 itens de divulgação desenvolvido por Bachmann et al. (2013). O arcabouço teórico utilizado procurou mostrar que a divulgação de informações ambientais, de forma voluntária, realizada pelas empresas por meio do Facebook pode ser explicada pela Teoria da Legitimidade.

Em relação à divulgação de informações foi constatado que metade das empresas analisadas utilizou o Facebook como canal para divulgar informações de caráter ambiental. Levando em consideração a dimensão que esta rede social possui, ela ainda está sendo pouco explorada pelas empresas como meio alternativo de divulgação de informações ambientais. Visto que esse canal acaba atingindo a diversos stakeholders, quando comparado com as formas tradicionais de divulgação por meio de relatórios específicos.

A análise descritiva mostrou que todos os 10 itens de divulgação foram divulgados por parte das empresas. Ao analisar essas divulgações, pode verificar que tratam de informações curtas e objetivas, sendo, a sua maioria, divulgada em formato de figuras e infográficos, porém, foi possível verificar que as empresas disponibilizavam o link de acesso ao relatório de sustentabilidade junto a essa divulgação.

Por meio dos mapas perceptuais, foi possível verificar que a divulgação de informações ambientais no Facebook, está associada ao setor de atuação no qual a empresa pertence, se ela faz parte de algum índice de sustentabilidade da B3 e também ao número de pessoas que seguem e curtem a página da empresa no Facebook.

Dadas estas observações, pode-se inferir que as empresas brasileiras atuantes em setores de maior impacto ambiental, que possuam um número médio de seguidores e que aparentam ser mais comprometidas com a sustentabilidade praticam um maior nível de evidenciação ambiental por meio do Facebook.

É possível perceber, também, que a divulgação de informações ambientais no Facebook ocorra como modo de buscar a legitimidade das ações das empresas, pois essa mídia social engloba diversos stakeholders.

Os resultados reforçam que a Teoria da Legitimidade explica a divulgação voluntária de informações ambientais, onde a empresa busca legitimar suas ações divulgando um quantitativo maior de informações ambientais adotando diferentes práticas de divulgação e que essas sejam percebidas por seus stakeholders como forma de atingir seus objetivos de continuidade no mercado.

Este estudo apresenta, como limitações, a análise de somente uma rede social, no caso o Facebook, a análise de um único ano e o uso de técnicas estatísticas de interdependência. Para futuros trabalhos, sugere-se investigar IEA em outras mídias sociais, tais como Youtube e Twitter, a fim de não somente comparar a adesão entre essas diferentes mídias, mas também avaliar este mesmo comportamento em amostras maiores. Recomenda-se, ainda, que se empreguem outras análises estatísticas, como modelos de regressão, para investigar fatores explicativos da divulgação voluntária alternativa, realizando-se a análise de informações de natureza ambiental, social e financeira.

\section{REFERÊNCIAS}

Aharony, J., \& Dotan, A. (2004). A comparative analysis of auditor, manager and financial analyst interpretations of SFAS 5 disclosure guidelines. Journal of Business Finance \& Accounting, $31(3-4), 475-504$. 
Arruda, M. P., de Sousa, R. A. M., Girão, L. F. D. A. P., \& Paulo, E. (2015). Divulgação de informações por meio da internet: serão as redes sociais capazes de reduzir a assimetria informacional entre empresas e investidores? Revista Evidenciação Contábil \& Finanças, 3(2), 27 41.

Bachmann, R. K., Carneiro, L. M., \& Espejo, M. M. (2013). Evidenciação de informações ambientais: proposta de um indicador a partir da percepção de especialistas. Revista de Contabilidade e Organizações, 7(17).

Bergamini Junior, S. (2000). Avaliação contábil do risco ambiental. Revista do BNDES, Rio de Janeiro, 7(14), 301-328.

Berthelot, S., Cormier, D., \& Magnan, M. (2003). Environmental disclosure research: review and synthesis. Journal of Accounting Literature, 22, 1.

Blankespoor, E., Miller, G. S., \& White, H. D. (2013). The role of dissemination in market liquidity: evidence from firms's use of twitter. The Accounting Review, 89(1), 79-112.

Bonsón, E., \& Bednárová, M. (2015). YouTube sustainability reporting: Empirical evidence from Eurozone-listed companies. Journal of Information Systems, 29(3), 35-50.

Botosan, C. A. (1997). Disclosure level and the cost of equity capital. The Accounting Review, 72(3), 323-349.

Botosan, C. A., \& Plumlee, M. A. (2005). Assessing alternative proxies for the expected risk premium. The accounting review, 80(1), 21-53.

Burson-Marsteller. 2010. The Global Social Media Check-Up 2010: Insights from the BursonMarsteller Evidence-Based Communications Group. Available at: http://www.bursonmarsteller.com/bm-blog/burson-marsteller-fortune-global-100-social-media-study/.

Cho, C. H., Freedman, M., \& Patten, D. M. (2011). Corporate disclosure of environmental capital expenditures: a test of alternative theories. Accounting, Auditing \& Accountability Journal, 25(3), 486-507.

Cho, C. H., Roberts, R. W., \& Patten, D. M. (2010). The language of US corporate environmental disclosure. Accounting, Organizations and Society, 35(4), 431-443.

Clarkson, P. M., Li, Y., Richardson, G. D., \& Vasvari, F. P. (2008). Revisiting the relation between environmental performance and environmental disclosure: An empirical analysis. Accounting, organizations and society, 33(4), 303-327.

Cormier, D., Gordon, I. M., \& Magnan, M. (2004). Corporate environmental disclosure: contrasting management's perceptions with reality. Journal of Business Ethics, 49(2), 143-165.

Dambrós, J.; Reis, C. A marca das redes sociais virtuais: Uma proposta de gestão colaborativa. In: Congresso Brasileiro de Ciências da Comunicação, 31., 2008, Natal. Anais... Natal: Intercom, 2008.

Dye, R. A. (1985). Disclosure of nonproprietary information. Journal of accounting research, 123145. 
Du, H., \& Jiang, W. (2014). Do social media matter? Initial empirical evidence. Journal of Information Systems, 29(2), 51-70.

Epstein, M. J., \& Freedman, M. (1994). Social disclosure and the individual investor. Accounting, Auditing \& Accountability Journal, 7(4), 94-109.

Eschenbrenner, B., Nah, F. F. H., \& Telaprolu, V. R. (2014). Efficacy of social media utilization by public accounting firms: findings and directions for future research. Journal of Information Systems, 29(2), 5-21.

Ernst \& Ernst (1973 et seq), Social responsibility disclosure, Ernst \& Ernst, Cleveland, OH. Fávero, L. P., Belfiore, P., Silva, F. D., \& Chan, B. L. (2009). Análise de dados: modelagem multivariada para tomada de decisões.

Fields, T. D., Lys, T. Z., \& Vincent, L. (2001). Empirical research on accounting choice. Journal of accounting and economics, 31(1), 255-307.

Fuji, A. H., \& Slomski, V. (2003). Subjetivismo responsável: necessidade ou ousadia no estudo da contabilidade. Revista Contabilidade \& Finanças, 14(33), 33-44.

Gibbins, M., Richardson, A., \& Waterhouse, J. (1990). The management of corporate financial disclosure: opportunism, ritualism, policies, and processes. Journal of accounting research, 121143.

Gomes, S. M. D. S., Oliveira, N. D. C., da Cruz, T. S., \& Oliveira, N. D. S. (2016). Evidenciação socioambiental de empresas baianas: uma análise na web 2.0 à luz da teoria da legitimidade. Sbijournal, (59).

Gonçalves, R. S., Ribeiro, M. O., Niyama, J. K., Weffort, E. F. J.; (2013). Social Disclosure e Custo de capital próprio em companhias abertas no Brasil. Revista Contabilidade \& Finanças - USP, Mayo-Agosto, 113-124.

Gray, R., \& Bebbington, J. (2001). Accounting for the environment. Sage.

Hackston, D., \& Milne, M. J. (1996). Some determinants of social and environmental disclosures in New Zealand companies. Accounting, Auditing \& Accountability Journal, 9(1), 77-108.

Hail, L. (2002). The impact of voluntary corporate disclosures on the ex ante cost of capital for swiss firms. The European Accounting Review, 11(4), 741-773.

Healy, P. M., Hutton, A. M. Y. P., \& Palepu, K. G. (1999). Stock performance and intermediation changes surrounding sustained increases in disclosure. Contemporary Accounting Research, 16(3), 485-520.

Healy, P. M., \& Palepu, K. G. (2001). Information asymmetry, corporate disclosure and the capital markets : a review of the empirical disclosure literature. Journal of Accounting and Economics, 31, 405-440.

International Integrated Reporting Council. (2013). The international framework. Recuperado de: http://www.theiirc.org/wp-content/uploads/2013/12/13-12-08-THE-INTERNATIONALIRFRAMEWORK-2-1.pdf 
Kiron, D., Palmer, D., Phillips, A. N., \& Kruschwitz, N. (2012). Social business: What are companies really doing? MIT Sloan management review, 53(4), 1.

Kothari, S. P., Shu, S., \& Wysocki, P. D. (2009). Do managers withhold bad news? Journal of Accounting Research, 47(1), 241-276.

Lenzen, M., Dey, C. J., \& Murray, S. A. (2004). Historical accountability and cumulative impacts: the treatment of time in corporate sustainability reporting. Ecological Economics, 51(3), 237-250.

Leuz, C., \& Verrecchia, R. E. (2000). The economic consequences increased disclosure. Journal of Accounting Research, 38(2000), 91-124.

Martinez, A. L., \& de Paula Faria, M. (2007). Emissão de debêntures e earnings management no Brasil. RIC-Revista de Informação Contábil-ISSN: 1982-3967, 1(2).

Mota, S. L., \& de Macedo Pinto, S. K. (2017). A utilização do twitter na análise do disclosure voluntário das empresas brasileiras com níveis diferenciados de governança corporativa. Revista Evidenciação Contábil \& Finanças, 5(1), 22-38.

Murcia, F. D. R., \& dos Santos, A. (2009). Fatores determinantes do nível de disclosure voluntário das companhias abertas no Brasil. Revista de Educação e Pesquisa em Contabilidade, 3(2), 72-95.

Nair, M. (2011). Understanding and measuring the value of social media. Journal of Corporate Accounting \& Finance, 22(3), 45-51.

Prokofieva, M. (2015). Twitter-based dissemination of corporate disclosure and the intervening effects of firms' visibility: Evidence from Australian-listed companies. Journal of Information Systems, 29(2), 107-136.

Rosa, F., Ensslin, S., \& Ensslin, L. (2010). Evidenciação ambiental: processo estruturado de revisão de literatura sobre avaliação de desempenho da evidenciação ambiental. Sociedade, Contabilidade e Gestão, 4(2). Recuperado em 16 de setembro de 2017, de http://www.atena.org.br/revista/ojs-2.2.308/index.php/ufrj/article/view/764/772

SEC. (2013). SEC says social media OK for company announcements if investors are alerted, Retrieved April 2, 2013 http://www.sec.gov/News/PressRelease/Detail/PressRelease/ 1365171513574\#.U5ppdPldXwg

Tinoco, J. E. P., \& Kraemer, M. E. P. (2004). Contabilidade e gestão ambiental. In Contabilidade e gestão ambiental. Atlas.

Trinkle, B. S., Crossler, R. E., \& Bélanger, F. (2015). Voluntary disclosures via social media and the role of comments. Journal of Information Systems, 29(3), 101-121.

Zhang, J. (2015). Voluntary information disclosure on social media. Decision Support Systems, 73, 28-36.

Zhou, M., Lei, L., Wang, J., Fan, W., \& Wang, A. G. (2014). Social media adoption and corporate disclosure. Journal of Information Systems, 29(2), 23-50. 
Data da submissão: 25/11/2017

Data de aceite: $26 / 10 / 2018$ 